\title{
ARGUMENTACIÓN Y FALACIAS EN LA LÓGICA DE PORT-ROYAL
}

MAURICIO BEUCHOT

INSTITUTO DE INVESTIGACIONES FILOLÓGICAS

Universidad NaCional AuTónoma de MÉxico

A Ezequiel de Olaso, in memoriam.

Ezequiel de Olaso abordó en diferentes ocasiones el problema de la argumentación, sobre todo en relación con el escepticismo, y de manera especial con respecto a la modernidad. Por eso me gustaría ahora ofrecer, en su honor, algunas reflexiones acerca del análisis que se hace de la argumentación falaz en la célebre Lógica de Port-Royal o Art de penser, debida a Pierre Arnauld y Pierre Nicole en el siglo xvir. Lo cumpliré haciendo una comparación con el tratamiento aristotélico de las falacias, para resaltar sus diferencias. Ya señalar en qué iban difiriendo será una ganancia para ver el paso de la historia misma de la teoría de la argumentación.

El tema de las falacias es importante para la teoría de la argumentación porque parece la otra cara de la moneda, esto es, lo que no se debe hacer al argumentar, la parte negativa, y eso ayuda mucho a la construcción de la parte positiva de la teoría de la argumentación. A pesar de que algunos han pensado que el estudio de las falacias no beneficia en nada, o muy poco, a la teoría argumentativa, creo que es al contrario: el señalamiento de los vicios puede ser guía y estímulo para ir hacia las virtudes. Así, al señalar las falacias que se cometen en los monólogos o en los diálogos argumentales, se está ayudando a mostrar lo que se debe evitar y a buscar lo que en verdad conviene hacer para lograr la validez en la inferencia y la fuerza en la prueba. ${ }^{1}$

El primero en sistematizar una lista o elenco de sofismas, de una manera sistemática, fue Aristóteles. Los dividió en sofismas debidos al lenguaje y

1 Más sobre esto puede verse en M. Beuchot-Édgar González Ruiz, Ensayos sobre teoría de la argumentación, Dirección General de Difusión Cultural, Universidad de Guanajuato, Guanajuato, 1993. 
sofismas debidos a la realidad. Los del lenguaje eran fallas gramaticales o semánticas, como el equívoco, la anfibología (o equívoco de toda una frase), el acento (o pronunciación mala, o mala prosodia, como "sabana" en lugar de "sábana"), la figura de dicción (como en "cuanto compraste te lo comiste, pero lo compraste crudo", luego te lo comiste crudo), la composición (como en "toco al golpeado con una piedra", ya que no se sabe si toco con una piedra al que fue golpeado, o toco al que fue golpeado con una piedra), de división ("cinco son dos y tres, luego cinco es dos y cinco es tres"). Los extralingüísticos son el sofisma de accidente ("este perro es tuyo, y es padre, luego es tu padre"), el de según algún respecto y de modo simple ("es un animal pintado, luego es animal"), de ignorancia del elenco ("la casa está cerrada por la noche y abierta por el día, luego está cerrada y no está cerrada"), de petición de principio ("Platón es hijo de Sócrates, luego Sócrates es padre de Platón"), de consecuente ("si es hombre es animal, luego si es animal es hombre"), de causa falsa (cuando se pone una premisa que no influye para nada en la conclusión), de pregunta múltiple (“iSócrates y Fido son hombres?" Si digo que sí, Fido, que es perro, sería hombre; si digo que no, Sócrates no sería hombre).

Los estoicos y los medievales dieron mayor sistematicidad a la enumeración de las falacias de Aristóteles. Sobre todo, en la Edad Media se buscaron los principios o criterios para la clasificación, y se encontraban en la metafísica aristotélica, es decir, en las ideas de sustancia y accidentes, en los tipos de accidente, en el esquema de las cuatro causas y la forma de disponerlas. Eran cosas ontológicas que se reflejaban en la lógica. Esto seguía muy de cerca la concepción medieval, tanto de los lógicos como de los gramáticos especulativos, de que la lógica refleja la estructura ontológica de la realidad. Por eso, una falla en la captación ontológica de las cosas repercute en la estructuración lógica de los pensamientos. Fueron célebres los tratamientos medievales de las falacias aristotélicas hechos por Tomás de Aquino y Pedro Hispano. El primero tendía más al realismo ontológico, y por ello insistía mucho en encontrar las bases metafísicas de esas fallas lógicas; ${ }^{2}$ en cambio, el segundo estaba más inclinado al terminismo o nominalismo, y le preocupaba más el tipo de defectos o errores inferenciales o de prueba que se cometían allí. ${ }^{3}$ Tal vez por eso fue lo suficientemente perspicaz para darse cuenta, por ejemplo, de que en la falacia de petición de principio lo que falla no es la inferencia formal, sino la fuerza probativa, y por eso

${ }^{2}$ Cfr. Santo Tomás, "Sobre las falacias", en el mismo, Opúsculos filosóficos selectos, trad. M. Beuchot, SEP, México, 1986, pp. 197-234; cfr. M. Beuchot, "Las falacias en la teoría de la argumentación de Santo Tomás de Aquino", en Convivium, Barcelona, no. 4, 1993, pp. 27-38.

${ }^{3}$ Cfr. P. Hispano, Tractatus, llamados después Summule logicales, trad. M. Beuchot, UNAM, México, 1986, pp. 74-166. 
llega a distinguir entre inferencia y prueba. ${ }^{4}$ No toda inferencia es prueba, o no todo vicio de prueba es vicio de inferencia. Así, en la falacia de petición de principio no hay paralogismo o defecto formal o inferencial, sino defecto material o de contenido. En esa falacia, de las premisas se sigue válidamente la conclusión, pero no alcanza a probar, ya que los elementos aducidos como prueba son lo mismo que lo que se quiere probar, también requieren prueba. Hay identidad proposicional entre el antecedente y el consecuente. El desarrollo de la reflexión sobre las falacias hecho por los lógicos medievales fue ciertamente notable.

En cambio, en la modernidad sucede algo curioso. La lógica formal decae, y se da la prioridad a los problemas epistemológicos. Al menos decae en comparación con la gran importancia que tuvo en los escolásticos medievales. El interés lógico deja lugar al epistemológico. Por eso el estudio de las falacias, hecho en la modernidad, adquiere aspectos sensiblemente diversos de los que tenía en la reflexión antigua y medieval. Hay un empobrecimiento lógico, y se da cabida a consideraciones harto diferentes, de cómo remediar los defectos de las operaciones mentales en su génesis y funcionamiento, no en su operatividad formal de esquema sintáctico y contenido semántico. Prevalece lo que podríamos llamar "lógica material" por encima de la lógica formal. Esto nos alecciona acerca del proceso histórico de la historia de la teoría de la argumentación -en este caso representada por la historia de las falacias-, que va aparejada a la historia misma de la filosofia, con sus cambios de intereses y de énfasis. Tributaria de los sesgos que ha dado la historia filosófica, la historia de las falacias muestra diferentes caras en las diferentes épocas por las que ha atravesado.

Así, será de interés examinar los cambios que significó la modernidad para el tratado de las falacias. En Aristóteles estuvo muy vinculada a su necesidad de combatir a los sofistas; en los estoicos estuvo muy vinculada a la construcción de una lógica más abarcadora, y por eso más sistematizada; y en la Edad Media estuvo más atenida a las preocupaciones metafísicas, de manera diferente en realistas y nominalistas; pero en ambas escuelas tuvo un carácter lógico-formal muy fuerte, y en la modernidad adquiere un aspecto más epistémico, por el cambio de problemas que se presentaban.

Precisamente, la Lógica de Port-Royal es un ejemplo de cambio de perspectiva en la historia del estudio de las falacias. A pesar de que considera las mismas falacias aristotélicas, lo hace de modo diferente a la Antigüedad y a la Edad Media: es un tratamiento más reducido y compendiado, y es un tratamiento aún más informal -es decir, más alejado de la lógica formal y entrado en el terreno de la "lógica informal" -, incluyendo más

4 Cfr. J. MacKenzie, "Confirmation of a Conjecture of Peter of Spain Concerning QuestionBegging Arguments", en Journal of Philosophical Logic, no. 13, 1984, pp. 35-45. 
consideraciones epistemológicas que puramente lógicas. Se ve ya el paso de lo medieval a lo moderno: el tránsito de lo lógico-ontológico a lo epistemológico. Este Art de penser añade a su material el tratado de las falacias sin mucho convencimiento, pues dice que, sabiendo las reglas del razonamiento correcto, se evitará el malo; pero, ya que los ejemplos de buenos razonamientos se hacen imitar, y los de malos razonamientos harán que se eviten, por eso les dedicará un espacio.

En la Logique, Arnauld, su autor, reduce el número de las falacias aristotélicas "a 7 u 8, habiendo algunas tan groseras que no merecen ser señaladas". ${ }^{5}$ Las que toma en cuenta son: (i) la falacia de ignorancia del elenco, (ii) la petición de principio, (iii) la de tomar como causa lo que no lo es, (iv) la falacia de accidente, (v) la falacia de composición y de división, (vi) la de según algún respecto y de modo absoluto o simple, (vii) la de ambigüedad y (viii) sacar una conclusión general de una inducción defectuosa. Esta última no corresponde a ninguna de la tabla aristotélica.

La ignoratio elenchi es tomada de Aristóteles y se la concibe como probar una cosa distinta de la que está en cuestión. Es simplemente la ignorancia de lo que hay que probar contra el adversario. No se alude a la ignorancia del modo de contradecir, sino simplemente a la de la conclusión que se ha de probar, con lo cual tiene ya un giro algo distinto del aristotélico. Ya no es tan formal, sino más epistémica. Por ejemplo, la mala fe puede hacer que en las discusiones cotidianas se cambie de asunto sin que el hombre de bien se dé cuenta. Incluso el Estagirita es acusado de haber incurrido en este vicio cuando atacaba a los filósofos anteriores a él. Pero también la Logique parece hacerlo, pues dice que Aristóteles acusaba sofísticamente a los anteriores de haber buscado un solo principio, entendiéndolo como principio de composición, mientras que lo entendían como principio originante, i.e., como Dios. ${ }^{6}$ Pero eso no es cierto en todos los casos, por lo menos no en el caso de Anaxágoras, por ejemplo. Y así el autor de la Logique parece ignorar lo que Aristóteles contradecía.

En cuanto a la petición de principio, se nos dice que en todo razonamiento lo que sirve de prueba debe ser más claro y conocido que lo que se ha de probar, y tal falacia transgrede esto. Estamos ante un sesgo más epistémico con relación a Aristóteles. Pero también acusa al Estagirita de haber caído en este sofisma, como lo hace ver Galileo cuando presenta a Aristóteles probando que la tierra está en el centro del universo porque las cosas pesadas tienden al centro de la tierra, y por eso la tierra, es el centro del universo. Pues que las cosas pesadas tienden al centro de la tierra es evidente, pero

5 Lart de penser. La logique de Port-Royal, edición facsimilar de la de 1662, FrommannHolzboog, Stuttgart-Bad Cannstatt, 1965, t. I, p. 254.

6 Cfr. lbid., p. 255. 
¿de dónde sacó que tiendan al centro del universo por tender al centro de la tierra? Está suponiendo lo mismo que debe mostrar: que ella es el centro del universo. También ve petitio el autor en la prueba que hacen los escolásticos de la causa formal o forma sustancial con base en la generación. Pues se dice que, si no hubiera formas sustanciales, no habría generación. Mas, como hay generación, luego hay formas sustanciales. ${ }^{7} \mathrm{Y}$, si esas formas perecen, con ello se les da armas a los libertinos para negar la inmortalidad del alma; pues hay algo que no es material —la forma sustancial-, que, sin embargo, se corrompe al corromperse el cuerpo. (Pero esta objeción contra los escolásticos surge de un malentendido, pues la forma sustancial que es el alma humana es una de tipo muy especial, a saber, espiritual, por lo que es inmortal; y no se necesita postular las dos sustancias - alma y cuerpo-, como Descartes y los cartesianos, para poder sostener la inmortalidad del alma. Puede hacerse postulando el alma espiritual como forma sustancial de la materia corpórea.)

Arnauld añade como otro modo de este sofisma argumentar por un principio que no es aceptado por el que disputa. Por ejemplo, para los católicos los dogmas no se pueden probar sólo por la Escritura, sino que también deben entrar otros elementos, como la tradición, la razón y el magisterio de la Iglesia. Y, si un anabaptista dice contra el católico que el bautismo de niños no está en las Escrituras, comete esta falacia, pues el católico sostiene que no todo lo que es de fe se saca de las Escrituras (sino también de la tradición, del magisterio eclesial o de la razón). Este modo es el más importante que registra la Logique, pues se trata de una petitio dialógica, en la que se toman en cuenta las creencias y las autoridades de los participantes en el diálogo. Otro modo de esta falacia es probar una cosa desconocida por otra igual o más desconocida; o una cosa incierta por otra igual o más incierta.

El sofisma de falsa causa o de la no causa como causa (non causa pro causa) es tratado enseguida. Uno de los modos del mismo es atribuir algo como efecto a una cosa que no es su causa, y esto se hace por ignorancia. Vemos otra vez el giro epistemológico de la Logique; ya no se trata, como en Aristóteles y la escolástica, de una falsa causa de la inferencia, esto es de una premisa irrelevante, que no se utiliza bien en la argumentación, sino de "ceguera" epistémica. Arnauld pone varios ejemplos tomados de la física, en los que los nuevos experimentos mostraron que había ignorancia de la verdadera causa. Otro modo es cuando se da una causa tan alejada, que no aclara nada de la cosa. Por ejemplo, Aristóteles quiso probar que hay tres movinientos alegando que hay tres dimensiones, y es difícil ver 
la consecuencia de una cosa a la otra. ${ }^{8}$ Aprovecha aquí para criticar a los escolásticos, pues dice que los que no quieren aceptar su ignorancia imaginan o fingen conocer la causa, con sólo atribuir a la cosa una virtud, por ejemplo, a las arterias una virtud pulsativa, al imán una virtud magnética, al sen una virtud purgativa y a la adormidera una virtud dormitiva. Todo lo cual suena a crítica de la virtus que adjudicaban los escolásticos como causas formales de las cosas. ${ }^{9}$ Pero otros son peores, pues engañan y dan como causa sus fantasías, por ejemplo, los astrólogos.

Así, uno de ellos, teniendo intento de probar por razones físicas la inmovilidad de la tierra, hizo una de estas principales demostraciones de esta razón misteriosa, que si la tierra girara en torno al sol, las influencias de los astros irian a través, lo cual causaría un gran desorden en el mundo. ${ }^{10}$

También hace pertenecer a este sofisma el error humano del post hoc, ergo propter hoc. Si algo ocurre después de algo, ese algo anterior fue su causa. Eso no es cierto, explica el autor, y es como atribuir a la estrella Canícula el calor que suele darse después de su aparición como si fuera causado por ella. Y se refiere a Gassendi, quien ha probado que eso no es verdad.

La falacia de accidente (fallacia accidentis) se da "cuando se saca una conclusión absoluta, simple y sin restricción de lo que sólo es verdadero por accidente". ${ }^{11}$ Como concluir que la medicina es mala porque se les han muerto pacientes a los médicos malos. Este sofisma ocurre también cuando se toman las ocasiones como si fueran verdaderas causas; por ejemplo, acusar a la religión cristiana de la muerte de muchos porque éstos se dejaban martirizar por los paganos antes que renegar del nombre de Cristo. Pone también como ejemplo el argumento de los epicúreos, según el cual los dioses debían tener forma humana, porque en todo el cosmos sólo el hombre tenía uso de razón. Pero no veían que en el hombre la sustancia que piensa y razona está unida al cuerpo sólo de manera accidental, no necesaria.

Las siguientes falacias, llamadas "de pasar del sentido dividido al sentido compuesto, o del sentido compuesto al sentido dividido", son las que la tradición denominaba fallacia compositionis y fallacia divisionis. Entienden el sentido compuesto implicando simultaneidad y el dividido implicando sucesividad. Así, lo que Cristo dice: "Los ciegos ven, los cojos andan y los sordos oyen", no puede entenderse en sentido compuesto, sino dividido,

8 Cfr. Ibid., p. 262.

9 Esto será ridiculizado por Molière en su comedia Le malad imaginaire, en la que el opio adormece porque tiene vis dormitiva, etcétera.

10 Logique, ed. cit., p. 265.

11 Ibid., p. 269. 
significando que los que eran ciegos han recibido la vista - dejando obviamente de ser ciegos-, etc. Lo que es verdadero en sentido compuesto y falso en sentido dividido puede presentarse como si fuera verdadero en el sentido incorrecto, y entonces es sofístico. Por ejemplo, tomar la oración citada, la del ejemplo de Cristo, en sentido compuesto - en que es falsay quererla presentar como verdadera, es falacia de composición. Y decir que no tiene caso arrepentirse, porque Dios condena a los pecadores, en sentido dividido -en que es falso- y quererlo presentar como verdadero, es falacia de división:

Es fácil ver que no se puede pasar sin sofisma de uno de esos sentidos al otro, y que, por ejemplo, razonarán mal los que se prometan el cielo permaneciendo en sus crímenes porque Jesucristo ha venido a salvar a los pecadores, y dijo en el Evangelio que las mujeres de mala vida precederán a los fariseos en el Reino de Dios. O quienes, al contrario, habiendo vivido mal, desesperando de su salvación, como no teniendo otra cosa que esperar sino el castigo de sus crímenes, porque se dijo que la cólera de Dios está reservada a todos aquellos que viven mal y que todas las personas viciosas no tendrán parte en la herencia de Jesucristo. ${ }^{12}$

En el primer caso, se está pasando del sentido dividido al sentido compuesto, pues se piensa que la salvación será simultánea al ser pecadores, mientras que se entendía para los que dejaran de serlo. En el segundo, se pasa del sentido compuesto al dividido, pues se aplica a los que han dejado de ser pecadores lo que es simultáneo al ser pecador.

Pero en esta presentación de la falacia por parte de la Lógica de PortRoyal no se encuentra ya la aplicación escolástica del sentido dividido y del sentido compuesto a las proposiciones modales, i.e., cuando se pasa de la modal en sentido compuesto (de dicto) a la que está en sentido dividido (de re). Al parecer, ese elemento de la tradición lógica se había perdido.

Otra falacia consiste en pasar de lo que es verdadero según algún aspecto a lo que es verdadero de modo simple, o de la verdad determinada, condicionada, o relativa a algo, a la verdad en sentido absoluto y sin más, lo que en la escolástica se llamaba a dicto secundum quid ad dictum simpliciter. Así, los estoicos pensaban que los dioses debían tener forma humana, porque es la más bella y noble, y lo más perfecto debe estar en Dios. Pero la forma humana no es la más bella de manera absoluta, sino de manera relativa a los cuerpos mortales. Arnauld se mofa y desprecia a los que incurren en una falacia tan poco sutil.

Otras falacias tratadas por Arnauld son las de equívoco y anfibología, que sólo enumera como "abuso de la ambigüedad de las palabras", aclarando

12 lbid., p. 272. 
que esto se puede hacer de varias maneras. Dice que a éstas pertenecen los silogismos con cuatro términos (sea porque el término medio se toma en una premisa como particular, o con un sentido en una y con otro en la otra, o porque los términos extremos se toman en la conclusión en sentido distinto del que tienen en las premisas). Se agrupan aquí todos los modos de equivocidad y se pide, para evitarla, que los términos sean definidos lo más preciso posible. ${ }^{13} \mathrm{Y}$ desprecia los casos en que el equívoco es muy grosero, para centrarse en los que engañan incluso a las personas hábiles. Por ejemplo, cuando el término puede tomarse como un todo colectivo o como un todo distributivo. Así es el sofisma de los estoicos que decían que el mundo es un animal dotado de razón, porque nada es mejor que lo que usa la razón; pero el mundo es lo mejor; luego usa la razón. ${ }^{14}$ La menor es falsa, porque atribuían al mundo lo que únicamente se puede atribuir a Dios. Pero, además, porque tomaban el mundo en sentido colectivo, y sólo podian tomarlo en sentido divisivo, es decir, dividiéndolo y diversificándolo según sus partes; pues tiene uso de razón sólo en algunas de sus partes, como los ángeles y los hombres, pero no como un todo. Esta falacia reúne y compendia varias de Aristóteles; y aquí la Logique de Port-Royal parece seguir una costumbre de algunos escolásticos tardíos — como Juan de Santo Tomás- de sintetizar la mayoría de las falacias lingüísticas en la de ambigüedad. ${ }^{15}$

El último tipo de sofisma de que se habla en la Logique es el de sacar una conclusión general de una inducción defectuosa. Esta falacia no aparece en las aristotélicas a título propio: Acaso se la podría ver en uno de los modos escolásticos de la petición de principio, que se daba al probar una conclusión o tesis universal dudosa con los particulares suyos, porque serían igualmente dudosos. Inducción es el paso de muchas cosas particulares al conocimiento de una verdad general. ${ }^{16}$ Comenzamos conociendo lo singular, aunque después el universal aprendido nos sirva para conocer mejor las mismas cosas singulares. Y por repetición de experiencias sobre lo particular alcanzamos las verdades universales, como de ver que un pueblo y otro y otro... tienen lenguaje, inferimos que todos los hombres lo tienen,

13 Esto es algo que concuerda con la obra de Pascal De l'esprit géometrique et de l'art de persuader, cfr. M. Beuchot, "Introducción" a B. Pascal, "Del espíritu geométrico y del arte de persuadir", en Tetraktys, Departamento de Matemáticas de la Universidad tberoamericana, México, 1987.

14 Cfr. Logique, ed. cit, p. 275.

15 Otro ejemplo es fray Benito Jerónimo de Feijóo; $c f r$. M. Beuchot-Édgar González Ruiz, "Fray Jerónimo de Feijóo y las falacias aristotélicas", en Estudios, ITAM, México, no. 8, 1987, pp. 73-84.

16 Cfr. Logique, ed. cit., p. 277. 
etc. Pero a veces la inducción se hace de manera defectuosa, como en el ejemplo que pone Arnauld:

Todos los filósofos habían creído hasta ahora, como una verdad indudable, que una jeringa, estando bien tapada, era imposible tirar el pistón sin hacerlo reventar, y que se podía hacer subir el agua tan alto como se quisiera por bombas aspirantes. Y lo que hacía creer esto tan firmemente es que se imaginaba que estaba asegurado por una inducción muy cierta, habiendo hecho una infinidad de experiencias. Pero una cosa y otra se encontraron falsas, porque se han hecho nuevos experimentos que han hecho ver que el pistón de una jeringa, por más tapado que esté, se puede tirar, provisto que se emplee una fuerza igual al peso de una columna de agua de más de treinta y tres pies de alto del grosor de la jeringa, y que no se podría levantar agua por una bomba aspirante más alto que de 32 a 33 pies. ${ }^{17}$

Vemos, así, que la Logique de Port-Royal, escrita por Arnauld en el siglo $\mathrm{xVII}$, recoge las falacias aristotélicas a través de la escolástica; pero, además de atacar algunas veces al propio Aristóteles y a los escolásticos, cambia el sentido general o mentalidad de las mismas, de una perspectiva más bien lógica formal, a otra preponderantemente epistemológica. Por lo demás, fusiona algunas de ellas en un tratamiento más somero - y olvidando varias de las aportaciones que habían logrado hacer los lógicos escolásticos-, y añade como otra de las falacias la de la inducción defectuosa o insuficiente.

Ezequiel de Olaso fue uno de los estudiosos de la historia de la teoría de la argumentación que más gustó de señalar estas diferencias y matices que distinguen el estudio de un tema o problema pasando de una época a otra. Así estudió el escepticismo en los griegos (tanto pirrónicos como académicos) y en los modernos. Por eso quise tratar de señalar la diferencia de enfoque que se puede marcar en el tratamiento moderno de las falacias, como es el de la Logique de Port-Royal por comparación con los escolásticos medievales. Esto se ve en los mismos escolásticos modernizados, sobre los que influyó mucho la lógica de Port-Royal, pues aun cuando seguían el esquema aristotélico-tomista de las falacias, ya incorporaban más elementos epistémicos de los que podían imaginarse en un tratado de lógica. Esto se ve en tratadistas escolásticos modernizados de la Nueva España, tales como Juan Benito Díaz de Gamarra y Dávalos, tratadista del siglo xviI. Ya eran otros tiempos. Pero eso también lo he tocado en otra parte. ${ }^{18}$

17 Ibid., p. 279.

18 Cfr. M. Beuchot, "Some Examples of Logic in New Spain (Sixteenth-Eigtheenth Century)", en I. Angelelli-M. Cerezo (eds.), Studies on the History of Logic, Walter de Gruyter, Berlín-Nueva York, 1996, pp. 215-228. 